\title{
Mass-conserving tracer transport modelling on a reduced latitude-longitude grid with NIES-TM
}

\author{
D. Belikov ${ }^{1}$, S. Maksyutov ${ }^{1}$, T. Miyasaka ${ }^{2}$, T. Saeki ${ }^{1}$, R. Zhuravlev ${ }^{3}$, and B. Kiryushov ${ }^{3}$ \\ ${ }^{1}$ National Institute for Environmental Studies, 16-2 Onogawa, Tsukuba 305-8506, Japan \\ ${ }^{2}$ Fujitsu FIP Corporation, Tokyo, Japan \\ ${ }^{3}$ Central Aerological Observatory, Dolgoprudny, Russia
}

Received: 2 September 2010 - Published in Geosci. Model Dev. Discuss.: 20 October 2010

Revised: 22 February 2011 - Accepted: 23 February 2011 - Published: 22 March 2011

\begin{abstract}
The need to perform long-term simulations with reasonable accuracy has led to the development of massconservative and efficient numerical methods for solving the transport equation in forward and inverse models. We designed and implemented a flux-form (Eulerian) tracer transport algorithm in the National Institute for Environmental Studies Transport Model (NIES TM), which is used for simulating diurnal and synoptic-scale variations of tropospheric long-lived constituents, as well as their seasonal and interannual variability. Implementation of the flux-form method requires the mass conservative wind fields. However, the model is off-line and is driven by datasets from a global atmospheric model or data assimilation system, in which vertically integrated mass changes are not in balance with the surface pressure tendency and mass conservation is not achieved. To rectify the mass-imbalance, a flux-correction method is employed. To avoid a singularity near the poles, caused by the small grid size arising from the meridional convergence problem, the proposed model uses a reduced latitude-longitude grid scheme, in which the grid size is doubled several times approaching the poles. This approach overcomes the Courant condition in the Polar Regions, maintains a reasonably high integration time-step, and ensures adequate model performance during simulations. To assess the model performance, we performed global transport simulations for $\mathrm{SF}_{6},{ }^{222} \mathrm{Rn}$, and $\mathrm{CO}_{2}$. The results were compared with observations available from the World Data Centre for Greenhouse Gases, GLOBALVIEW, and the Hateruma monitoring station, Japan. Overall, the results show that the proposed flux-form version of NIES TM can produce tropospheric tracer transport more realistically than previously possible. The reasons for this improvement are discussed.
\end{abstract}

Correspondence to: D. Belikov

(dmitry.belikov@nies.go.jp)

\section{Introduction}

Global three-dimensional chemistry transport models (hereafter referred to as CTMs), driven by actual meteorology from numerical weather predictions, and global circulation models (GCMs) play a crucial role in assessing and predicting change in the composition of the atmosphere due to anthropogenic activities and natural processes (Rasch et al., 1995; Jacob et al., 1997; Denning et al., 1999; Bregman et al., 2006; Law et al., 2008; Maksyutov et al., 2008; Patra et al., 2008). Forward modelling is used to estimate tracer concentrations in regions that lack observation data and to identify the features of tracer transport and dispersion (Law et al., 2008; Patra et al., 2008). Inverse methods are generally applied when interpreting the data, with atmospheric transport models providing the link between surface gas fluxes and their subsequent influence on atmospheric concentrations (Rayner and O'Brien, 2001; Patra et al., 2003a, b; Gurney et al., 2004; Baker et al., 2006).

There are several factors that strongly influence model performance: the numerical transport algorithm, meteorological data, grid type, and resolution. In tracer transport calculations, semi-Lagrangian transport algorithms are often used in combination with finite-volume models. Losses in the total tracer mass are possible in these algorithms. While such losses are often negligible for short-term transport simulations, they can seriously distort the global trends and tracer budgets in long-term simulations. To avoid such losses, various mass-fixing schemes have been applied (Hack et al., 1993; Rasch et al., 1995). Although the use of mass fixers can prevent mass losses, there remains a possibility of predicting distorted tracer concentrations. In contrast, when using a flux-form transport algorithm, the total tracer mass is conserved and thus the issue of mass losses can be eliminated, provided the flow is conservative. The use of numerical schemes with limiters leads to distorted tracer

Published by Copernicus Publications on behalf of the European Geosciences Union. 
concentrations and affects the linearity. Thus, to accurately calculate the tracer concentration in a forward simulation and to use the model in inverse modelling, we developed a flux-form version of the National Institute for Environmental Studies off-line global Transport Model (NIES TM).

To avoid a singularity near the poles caused by small grid size associated with the meridional convergence problem, the proposed version uses a reduced latitude-longitude grid scheme (Kurihara and Holloway, 1967; Prather et al., 1987; Williamson, 1992; Rasch, 1994) in which the grid size is doubled approaching the poles. Consequently, it is possible to run simulations without reducing the time step. Although Bregman et al. (2006) described the pitfalls of polar model grid averaging in global model studies of polar tracer transport in the stratosphere, numerical advection schemes that use a reduced grid generally perform well in model performance tests and are efficient solvers in various applications (Peterson et al., 1998).

An alternative way of solving the singularity problem is the Lagrangian remapping method (Colella and Woodward, 1984; Lin and Rood, 1996; Lin, 2004), in which mass can be transported across several grid cells in a single time step. The Flux-Form Semi-Lagrangian Transport scheme (FFSL), as proposed by Lin and Rood (1996), is unconditionally stable for nondeformational flows and has less-restrictive limitations than the normal Courant number for deformational flows. A drawback of this scheme is the difficulty encountered in implementing the parallel algorithm using domain decomposition in the longitude direction on a regular grid, requiring occasional communications across several neighbouring domains. This problem complicates the design of a parallel code with 3-D decomposition, which is desirable for use on computer systems with thousands of cores. The replacement of the Courant-Friedrichs-Lewy (CFL) with Lifshitz criteria (Prather et al., 2008) is also way of solving the singularity problem.

Other ways for avoiding the numerical difficulties of the spherical poles are using the icosahedral (Niwa, 2010) and cubic grids (Putman and Lin, 2007). The influence of grid resolution on atmospheric composition simulation is a topic of continuous interest. Marchand et al. (2003) and Bregman et al. (2006) reported that grid resolution has a strong influence on the distribution of the tracer mixing ratio in the Polar Regions. In contrast, van den Broek et al. (2003) reported a negligible improvement in methane transport model results with increasing horizontal grid resolution to $1^{\circ} \times 1^{\circ}$ in a study on the effect of spatial resolution in the Polar Regions. A significant sensitivity to horizontal resolution was reported by Strahan and Polansky (2006), Patra et al. (2008) and Prather et al. (2008). Searle et al. (1998) noted that the sensitivity of the model results to the resolution depends on the diffusivity of the advection scheme.

The quality of wind data provided by numerical weather predictions is another crucial factor for tracer transport (Jöckel et al., 2001; Stohl et al., 2004; Bregman et al.,
2006). Wind fields produced by the Data Assimilation System (DAS) are commonly used for driving CTMs. Spurious variability or "noise" introduced via the assimilation procedure affect the quality of meteorological data through a lack of suitable observations or by the inaccurate treatment of model biases (Bregman et al., 2006). This negative effect is proportional to the dynamic time scale and increases with operational time. The most sensitive area in this regard is the lower stratosphere in tropical regions, where large volumes of air move upward from the troposphere to the stratosphere. A lack of observations makes this region the most challenging in terms of data assimilation. Bregman et al. (2006) found that the modeled vertically integrated mass change obtained for the tropical atmosphere is not in geostrophic balance with the surface pressure tendency. Schoeberl et al. (2003) suggested that GEOS DAS is less suitable for longterm stratospheric transport studies than wind from a general circulation model. At the same time, improvements to the data assimilation system itself (ECMWF ERA-Interim reanalysis; Dee and Uppala, 2009) and the development of special products for use in transport models (MERRA: Modern Era Retrospective-analysis for Research and Applications; Bosilovich et al., 2008) have assisted in improving the accuracy of atmospheric circulation when using off-line models (Monge-Sanz et al., 2007).

The remainder of this paper is organized as follows. Section 2 provides information on the model and a detailed description of the meteorology dataset and flux correction procedure. In Sect. 3, we evaluate flux-form versions of the NIES TM, including testing of numerical schemes, calculations with high-resolution grids, assessment of the meteorological datasets, and a comparison with observations and with a Semi-Lagrangian version of NIES TM evaluated via participation in TransCom intercomparison experiments. Finally, a summary and conclusions are provided in Sect. 4.

\section{Model description}

We designed a new version of NIES TM (denoted NIES-08) with flux-form advection algorithms. As with the previous model, which used semi-Lagrangian algorithms (Maksyutov et al., 2008), we used a terrain following $\sigma$ vertical coordinates and presented the atmospheric constituent transport equation in the Lagrangian-style form (Willamson and Laprise, 2000):

$$
\begin{aligned}
\frac{d q^{k}}{d t} & =\frac{\partial q^{k}}{\partial t}+\boldsymbol{V} \cdot \nabla_{\sigma} q^{k}+\dot{\sigma} \cdot \frac{\partial q^{k}}{\partial \sigma} \\
& =\frac{\partial}{\partial \sigma} F^{k}+S^{k} \nabla_{\sigma}=\frac{\partial}{R \cos (\phi) \partial \lambda}+\frac{\partial}{R \partial \phi}
\end{aligned}
$$

where $q^{k}$ is the $k$-th tracer mixing ratio (volume) in dry air; $\boldsymbol{V}$ is a vector of horizontal wind velocity, which consists of longitudinal and latitudinal components $(u, v)$ interpolated 
from the global analysis winds; $\dot{\sigma}$ is the vertical wind velocity component; $F^{k}$ is the vertical sub-gridscale flux caused by moist convective transport and turbulent diffusion, as obtained using parameterizations of the penetrative cumulus convection and PBL climatology; $S^{k}$ is the mixing ratio tendency due to surface fluxes and chemical transformations; $\lambda$ and $\phi$ are longitude and latitude (in radians), respectively; and $R$ is the radius of the Earth.

\subsection{Horizontal mass-flux correction}

Because the three-dimensional flux-form NIES-08 transport model accepts input field data in the form of mass fluxes integrated on cell volume interfaces, it is necessary to interpolate the wind fields on a regular grid and to integrate the wind fields over the boundaries of grid cells. A problem of this approach is that the vertically integrated mass change is not in balance with the surface pressure tendency and mass conservation is not achieved. This drawback has been recognized as the mass imbalance problem, and various methods have been developed to minimize such inconsistencies in the derivation of mass fluxes (Heimann and Keeling, 1989; Rotman et al., 2004). In the most consistent correction method, designed by Segers et al. (2002), horizontal mass fluxes are derived directly from the spectral vorticity and divergence, resulting in a more accurate approximation of the fluxes on cell volume interfaces and providing higher-quality mass-conserving wind fields that require less mass-balance correction. However, this method uses spectral fields (vorticity and divergence), which are not available for some meteorological datasets used in off-line models such as NIES TM. As a result, in the present model, horizontal mass fluxes are computed following a more commonly employed method developed by Heimann and Keeling (1989) (see also Bregman et al., 2003).

Data processing is performed in three steps. For each moment in time of the original meteorological analyses, the horizontal mass fluxes are obtained by vertical-meridional and vertical-zonal integration. The model then assumes that the mass flux fields are valid during an entire meteorological time step, while the surface pressure, which determines the atmospheric mass distribution, is defined at the beginning and end of each meteorological time step (Heimann, 1995).

The conservation of mass requires that the vertically integrated air-mass convergence equals the surface pressure tendency. The horizontal mass fluxes, $\vec{\Phi}_{h}=\left(\Phi_{u}, \Phi_{v}\right)$, derived from the meteorological dataset are balanced with the surface pressure tendency by adding correction fluxes, $\vec{F}_{c}$, which are determined as follows:

$\vec{\delta}\left(\vec{\Phi}_{h}(l)+\vec{F}_{c}(l)\right)=-\frac{\partial m_{s}(l)}{\partial t}, l=1, . ., N$

where $\vec{\delta}$ is a horizontal difference operator between opposite boundaries of a grid cell, $l$ represents the vertical grid layer, and $m_{s}(l)$ denotes the mass in the cell, defined as the product of pressure $p(l)$ on the current level and the grid cell area $A$ divided by gravitational acceleration $g$ $\left(m_{s}(l)=p(l) A / g\right)$. The pressure changes are the multiplication of sigma by the surface pressure changes which are calculated from two pressure fields at different time points. Equation (2) is first solved for the single correction flux $\vec{F}_{c}$ :

$\vec{\delta} \vec{F}_{c}(l)=-\vec{\delta} \vec{\Phi}_{h}(l)-\frac{\partial m_{s}(l)}{\partial t} ; l=1, . ., N$

The correction flux is calculated by transforming Eq. (3) into a Poisson equation, which is solved with a discrete 2D Fourier transform. This procedure is performed $N$ times for each vertical grid layer $l$ independently, yielding the corrected air mass flux, which is subsequently added to the vertical flux.

\subsection{Numerical methods}

The semi-Lagrangian transport algorithm is an effective way to solve tracer transport problems (Williamson and Rasch, 1989). In the semi-Lagrangian approach, formulated in a polar coordinate system, the tracer concentration change due to transport from the initial state to a new value at the next time step is evaluated in two steps: trajectory calculation and interpolation (Maksyutov et al., 2008). The trajectories are calculated using explicit integration of the air parcel motion in the Cartesian coordinate system with an origin at the Earth's center. A coordinate transformation, from polar to Cartesian systems and back again, is used at each time step. This method avoids problems associated with a singularity near the poles, in contrast to regular-grid schemes formulated in flux form, which have a decreasing grid size in the longitudinal direction.

The need to use a higher spatial resolution and to perform the calculations associated with long-term tracer transport demands an efficient advection and strict mass conservation scheme with high accuracy (Petersen et al., 1998). Unfortunately, the semi-Lagrangian algorithm cannot meet this requirement, because it requires a global mass fixer (Rash, 1994). To overcome this problem, we designed a flux-form version of NIES TM with the third-order van Leer scheme (van Leer, 1977) and second-order moments advection scheme developed by Prather (1986). According to the van Leer scheme, the tracer concentration on the edge of the control volume can be determined using the difference between the known values (the shape of the concentration), assuming a second-order polynomial to represent the inner-cell concentration. Advective flux through the face is determined by the shape of the concentration between the edge and the nearest node on the leeward side.

The main advantages of the well-known second-order moments advection scheme are accuracy, stability, conservation, and small numerical diffusion. To obtain the fluxes at cell interfaces from cell center values, this scheme prognostically simulates the evolution of the first- and second-order moment 
of the mixing ratio. The traditional technique (method of alternating directions) is used and the three-dimensional transport is decomposed into three one-dimensional fluxes that act successively: $X \rightarrow Y \rightarrow Z$. In other words, each advection step is divided into four longitudinal steps, two latitudinal steps, and one step in the vertical direction. Such a detailed and accurate technique for calculation leads to a multifold increase in the costs of central processing unit (CPU) time and memory compared with schemes based on van Leer's approach (Petersen et al., 1998).

\subsection{Meteorology data used in the model}

In this study, we use two meteorological datasets produced by global spectral numerical models, as outlined below.

\subsubsection{GFS meteorology data}

The National Centers for Environmental Prediction (NCEP) meteorology data are the product of the global spectral numerical Global Forecast System (GFS) model based on primitive dynamical equations that include a suite of parameterizations for atmospheric physics (Kalnay et al., 1990). The current GFS version has a spectral triangular truncation of 382 waves (T382) in the horizontal (equivalent to nearly a $35 \mathrm{~km}$ Gaussian grid), and a hybrid sigma-pressure finite differencing system in the vertical with 64 layers (Moorthi et al., 2010). For the purpose of the present study, we used the official product with a resolution of $1.0^{\circ} \times 1.0^{\circ}$ and 25 pressure levels. The model has been under constant development and evaluation. For an overview of the major changes made to the model from 2001 to 2004, see Yang et al. (2006); for the most recent detailed information, see Moorthi et al. (2010).

\subsubsection{GPV meteorology data}

The NIES tracer transport model uses an enhanced version of the Global Point Value (GPV) meteorological dataset with a resolution of $0.5^{\circ} \times 0.5^{\circ}$ for 21 pressure levels. GPV is a special product prepared by the Japan Meteorological Agency Global Circulation Model (JMA-GSM), which is a high-resolution global atmospheric circulation model developed by the Japan Meteorological Agency (JMA) and the Meteorological Research Institute (MRI) of Japan, for use in both climate simulations and weather prediction (Mizuta et al., 2006). The current version of the model uses a reduced Gaussian grid TL959L60 with a resolution of approximately $20 \mathrm{~km}$ in the horizontal and 60 layers up to $0.1 \mathrm{hPa}$ in the vertical (Iwamura and Kitagawa, 2008). The model is able to simulate climate and atmospheric processes with high accuracy, due to a two-time-level, semi-implicit vertically conservative semi-Lagrangian scheme (Yoshimura and Matsumura, 2003) and fourth-order horizontal diffusion, improved physics, better representation of topographical effects, and improved distribution of seasonal precipitation and zonal-mean wind (Mizuta et al., 2006; Nakagawa, 2009).
The use of a high-resolution grid means that many smallerscale phenomena are represented explicitly. GPV preserves the conservation of a vertically integrated quantity under the non-dissipative condition, due to the development of a vertically conservative semi-Lagrangian scheme in which vertical advection is treated separately from horizontal advection (JMA, 2007). An advantage of GPV data is their availability in near-real time (delay of several hours), meaning that the transport model can be used in quasi-online mode. To set adequate mixing in the near-surface layer of the atmosphere, the 3-hourly height of the planetary boundary layer (HPBL) is taken from the ECMWF Interim Reanalysis (Simmons et al., 2006, 2007), as HPBL data are not included in the original GPV data set.

The meteorological fields are interpolated to the model grid using bi-linear interpolation to the cell center. They are mapped to the center of cell interfaces. Turbulent diffusivity is similar to described by Maksyutov et al. (2008): above the PBL top the approach of Hack et al. (1993) is used, below the PBL top, the turbulent diffusivity is set to a constant value of $40 \mathrm{~m}^{2} \mathrm{~s}^{-1}$. The 3-hourly planetary boundary layer height is taken from the GFS data or ECMWF Interim Reanalysis. The same scheme of turbulent diffusivity was implemented for semi-Lagrangian and flux-form versions.

\subsection{Vertical coordinate and horizontal grid}

"Noise" appearing through the horizontal mass flux correction method (Sect. 2.1) may affect the quality of meteorology (Bregman et al., 2006). The influence of spurious variability is greater in the vertical component of the wind vector. The increased value of vertical movement may cause erroneously enhanced mixing and mass transport from the bottom of the atmosphere to the top. The loss of mass at the near-surface layer results in distortion of tracer seasonal variability via a decrease in amplitude. The most error-prone situation occurs at the border between the troposphere and stratosphere, where extra mixing leads to erroneously large exchange between layers. One of the consequences of this enhanced exchange is increased dispersion and an enforced large-scale stratospheric circulation that leads to a reduction in the residence time of tracers (Schoeberl et al., 2003).

The use of a high-resolution model grid yields high surface-elevation gradients and hence rapid changes in surface pressure within a computational cell with a size on the order of $50 \mathrm{~km}$. Thus, perturbations caused by a sharp rise in pressure at the surface can extend to high levels (much higher than in the real atmosphere). The increased horizontal resolution in the meteorology model grid means that the size of each grid cell is smaller and the vertical velocity is resolved to a greater degree horizontally; consequently, the amplitude of vertical velocity increases (Mizuta et al., 2006). Figure 1 shows the monthly averaged vertical wind, from the GPV and GFS datasets, over Japan for January 2008. The figure shows regions with high surface heterogeneity (mountains, 

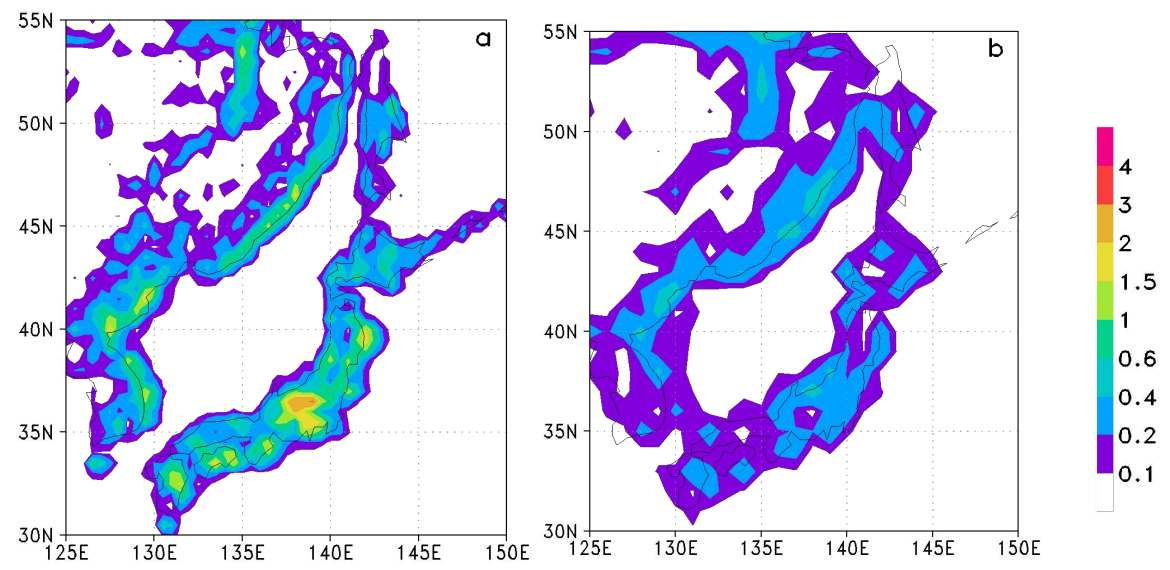

Fig. 1. Monthly averaged vertical component of the wind vector $\left(10^{-5} \mathrm{~Pa} \mathrm{~s}^{-1}\right)$ over Japan, as obtained using the (a) GPV and (b) GFS datasets for January 2008.

coastal regions) where local vertical velocity in the GPV dataset shows a marked increase, 2-4 times greater than the increase in the GFS dataset. This increase in velocity slows the speed of computation (due to the Courant condition) and, of most concern, enhances vertical mixing along the entire height range. As a result, the mean age of the air in the stratosphere drops to 1 yr or less.

To avoid these undesirable consequences, it is necessary to implement an appropriate approach such as hybrid $\sigma-p$ vertical coordinates (Chipperfield, 2006). A hybrid vertical grid has the properties of sigma coordinates in the lower part of the atmosphere (up to $300 \mathrm{hPa}$ ), where strong vertical mixing occurs, meaning that extra mixing due to the implementation of a correction method for horizontal mass flux and the use of high-resolution meteorological data has no unintended consequences and cannot disrupt the structure. In the upper part, above $300 \mathrm{hPa}$, pressure levels are used (Kalnay, 2002). The interface between these two parts of the vertical coordinate is similar to a border that prevents the penetration of fluctuations related to surface-pressure oscillations and that prevents erroneous vertical wind from the troposphere to the stratosphere. The vertical grid has 25 levels.

To avoid a singularity near the poles, caused by the small grid size associated with the meridional convergence problem, this model uses a reduced latitude-longitude grid scheme (Prather et al., 1987; Williamson, 1992; Rasch, 1994) in which the grid size is doubled if the condition $\Delta x>$ $0.5 \Delta y(\Delta x, \Delta y$ are longitude and latitude step, respectively) is violated. Dependence of the nesting level on latitude for resolutions of 1.25 and 2.5 deg are presented in the Fig. 2. Consequently, it is possible to run simulations with a larger time step. Following Maksyutov et al. (2008), the first model grid cell is located near the South Pole, between $\left(0^{\circ} \mathrm{E}, 90^{\circ} \mathrm{S}\right)$ and $\left(2.5^{\circ} \mathrm{E}, 87.5^{\circ} \mathrm{S}\right)$, and the last is located at the North Pole, between $\left(357.5^{\circ} \mathrm{E}, 87.5^{\circ} \mathrm{N}\right)$ and $\left(0^{\circ} \mathrm{E}, 90^{\circ} \mathrm{N}\right)$.

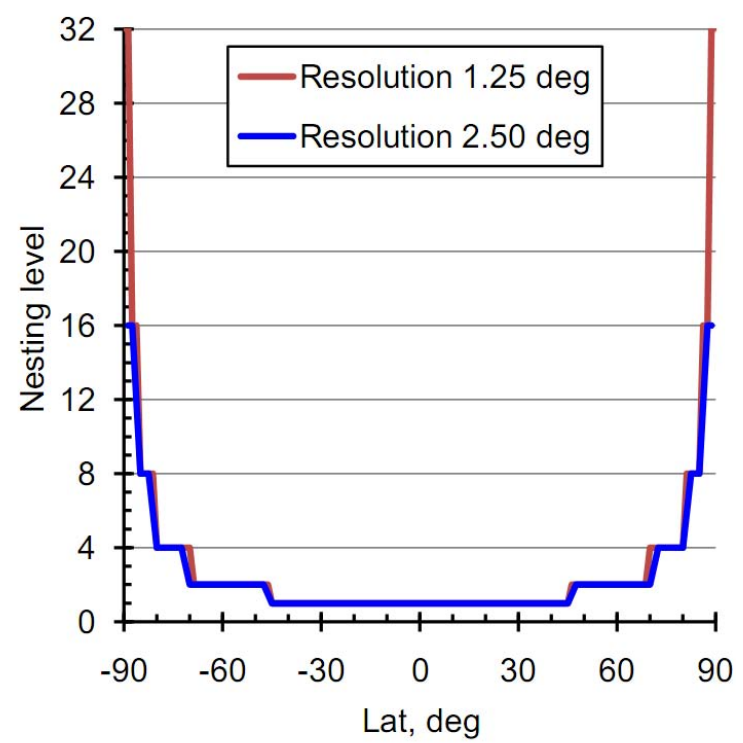

Fig. 2. Dependence of the nesting level on latitude for resolutions of 1.25 and $2.5^{\circ}$.

\section{Evaluation of the NIES global transport model}

Here, we evaluate the proposed model with flux-form advection algorithms. The model results are compared with the results obtained using a semi-Lagrangian model. The semi-Lagrangian version of NIES-08 is generally similar to previous releases (NIES-05, -99), which were evaluated in forward and inverse mode through participation in The Atmospheric Tracer Transport Model Intercomparison Project (TransCom) model intercomparison (Gurney et al., 2003, 2004; Law et al., 2003, 2008; Patra et al., 2003a, 2008). The performance achieved in these tests indicates that the model is a powerful tool in studying global atmospheric transport. However, problems were identified, indicating a 
need to improve the model. The improvements are implemented in the new version of the model, as described in this paper. Therefore, in testing NIES-08 TM below, we seek to improve on the results obtained with NIES-05.

\subsection{Numerical methods test}

Previous studies have tested Prather's (1986) numerical schemes and those schemes based on a van Leer numerical algorithm (Williamson and Rasch, 1989; Petersen et al., 1998). However, these works were concerned mainly with test cases or were limited to short simulations with real atmosphere data and a coarse resolution. The real performance of each numerical algorithm varies considerably depending on implementation, meteorological data, and spatial resolution. In this study, we assessed the implementation of semiLagrangian and flux-form advection numerical algorithms on a reduced grid for tracer transport.

To estimate the performance of advection schemes, we performed repeated tests of solid-body rotation on a sphere. The model transport equation (Eq. 1) is solved without the source and the chemical reaction term $S^{k}$. The initial tracer fields were specified in the form of cones at the North and South Poles:

$q(\lambda, \varphi)=3 \sin ^{2}(\varphi), \varphi=[-\pi / 2 ; \pi / 2], \lambda=[0 ; 2 \pi]$

The velocities are given by Smolarkiewicz and Rasch (1991) and Petersen et al. (1998):

$u=\dot{\lambda} \cos \varphi=U(\cos \beta \cos \varphi+\sin \beta \sin \varphi \cos \lambda), v=\dot{\varphi}=-U \sin \beta \sin \lambda$.

In the simultation using the proposed model, we set an arbitrary angle $\beta=\pi / 2$. For the chosen angle beta two tracer fields are rotating over the globe from pole to pole. Coneshaped tracer field goes along meridian $90^{\circ} \mathrm{E}$ from the North to the South Pole, and goes back along meridian $90^{\circ} \mathrm{W}$, passing through the Polar Regions, which are the most potentially uncertain regions because of reduced grid size. The vertical velocity component is equal to zero.

In this test, we use three version of NIES TM: one with a semi-Lagrangian algorithm (SML), one with the van Leer (VL) numerical scheme, and one with Prater's second-order moments (Pr) numerical scheme. Table 1 lists the results of the solution of the solid-body rotation test and the performances of the model versions at three different resolutions. Test simulations were performed on a vector supercomputer NEC SX-8R. Evaluations of the memory and CPU use took into consideration the cost of reading and processing the meteorological data, as in the case of real global-transport simulations. The error measures are the same as those in Petersen et al. (1998) and Smolarkiewicz and Rasch (1991):

$e_{\min }=\frac{\min \left(q_{\lambda, \varphi}^{n}\right)-\min \left(q_{\lambda, \varphi}^{0}\right)}{\max \left(q_{\lambda, \varphi}^{0}\right)}$, $e_{\max }=\frac{\max \left(q_{\lambda, \varphi}^{n}\right)-\max \left(q_{\lambda, \varphi}^{0}\right)}{\max \left(q_{\lambda, \varphi}^{0}\right)}$,

$\operatorname{err} 1=\frac{\sum q_{\lambda, \varphi}^{n} \gamma_{\varphi}}{\sum q_{\lambda, \varphi}^{0} \gamma_{\varphi}}-1$,

$\operatorname{err} 2=\frac{\sum\left(q_{\lambda, \varphi}^{n}\right)^{2} \gamma_{\varphi}}{\sum\left(q_{\lambda, \varphi}^{0}\right)^{2} \gamma_{\varphi}}-1$.

These quantities represent the minimum value minus the true minimum value normalized by the true maximum value, the maximum value minus the true maximum value normalized by the true maximum value, the normalized errors of the mean, and the field variance, respectively. $E_{\max }$ is influenced by numerical diffusion and overshoot, and $e_{\min }$ is influenced by numerical diffusion and undershoot.

Among the three models, the version with a semiLagrangian scheme shows the best performance and weak dispersion of concentrations because of small numerical diffusion. The normalized errors of the mean (err1) and the variance of the field (err2) show that the form of the initial cones was substantially changed. Moreover, this scheme gives considerable overshoot. $E_{\max }$ should be less than or equal to zero, and $e_{\text {min }}$ should be greater than or equal to zero, because advection does not generate a new extreme (Petersen et al., 1998).

The van Leer's scheme maintains the shape of the profile. Decreases in $e_{\max }$ and $e_{\min }$ with increasing resolution indicate that these quantities are influenced by numerical diffusion but not by overshoot or undershoot. The performance and memory cost of this scheme are reasonable for longterm, high-resolution simulations.

The second-order moments approach includes a limiter preventing negative values of tracer mixing ratio, resulting in small overshoot and undershoot. However, a major disadvantage of it is the need for greater computing time and memory demand. We used a standard code of Prather scheme (Prather, 1986), because numerical model optimization in order to achieve high performance on vector computer systems requires additional time-consuming efforts. Apparently the non-optimized second-order moment's scheme is less adopted to work with high efficiency on NEC vector machines. Nevertheless high CPU time and memory demand of this scheme in comparison with others was marked by Petersen et al. (1998).

Thus, the van Leer scheme represents a compromise solution, as it has acceptable accuracy, conserves the mass of the tracer, and at the same time provides sufficient performance to carry out calculations with high resolution. 
Table 1. Performance of the schemes implemented in the model NIES TM. Here, NIES-08 $\backslash$ SML, NIES-08 VL, and NIES-08 $\backslash$ Pr denote NIES TM with semi-Lagrangian, van Leer's, and Prater's numerical schemes, respectively. Err1 is normalized errors of the mean, err2 is variance of the field, $e_{\max }$ is overshoot of the scheme, and $e_{\min }$ is undershoot of the scheme.

\begin{tabular}{llrrr}
\hline Resolution & & NIES-08 $\backslash$ SML & NIES-08 $\backslash$ VL & NIES-08 $\backslash$ Pr \\
\hline \multirow{3}{*}{$2.5^{\circ} \times 2.5^{\circ}$} & CPU, sec & 6.08 & 10.21 & 292.90 \\
& $e_{\min }$ & $-5.37 \mathrm{E}-03$ & $6.22 \mathrm{E}-04$ & $1.38 \mathrm{E}-04$ \\
& $e_{\max }$ & $2.16 \mathrm{E}-03$ & $-2.86 \mathrm{E}-03$ & $-3.48 \mathrm{E}-04$ \\
& err1 & $6.09 \mathrm{E}-02$ & $-6.66 \mathrm{E}-03$ & $-5.96 \mathrm{E}-08$ \\
& err2 & $5.08 \mathrm{E}-03$ & $1.17 \mathrm{E}-03$ & $1.02 \mathrm{E}-03$ \\
& Memory, GB & 0.72 & 0.72 & 0.77 \\
\hline \multirow{5}{*}{$1.25^{\circ} \times 1.25^{\circ}$} & 20.86 & 55.93 & 1755.77 \\
& CPU, sec & $-0.229 \mathrm{E}-06$ & $1.57 \mathrm{E}-04$ & $-5.95 \mathrm{E}-05$ \\
& $e_{\min }$ & $0.00 \mathrm{E}+00$ & $-3.66 \mathrm{E}-03$ & $1.03 \mathrm{E}-06$ \\
& $e_{\max }$ & $1.93 \mathrm{E}-02$ & $-3.50 \mathrm{E}-03$ & $4.78 \mathrm{E}-03$ \\
& err1 & $9.90 \mathrm{E}-03$ & $8.94 \mathrm{E}-04$ & $8.48 \mathrm{E}-03$ \\
& err2 & 0.98 & 0.98 & 1.10 \\
\hline Memory, GB & 82.20 & 370.975 & 12683.15 \\
& CPU, sec & $-1.04 \mathrm{E}-07$ & $3.93 \mathrm{E}-05$ & $-5.11 \mathrm{E}-06$ \\
& $e_{\min }$ & $7.95 \mathrm{E}-08$ & $-2.44 \mathrm{E}-03$ & $-5.21 \mathrm{E}-03$ \\
& $e_{\max }$ & $1.59 \mathrm{E}-02$ & $-1.75 \mathrm{E}-03$ & $5.55 \mathrm{E}-03$ \\
& err1 & $1.74 \mathrm{E}-02$ & $6.15 \mathrm{E}-04$ & $1.18 \mathrm{E}-04$ \\
& err2 & 1.94 & 1.94 & 2.46 \\
\hline & Memory, GB & & &
\end{tabular}

\subsection{Model evaluation by comparison of simulated results with observations}

In the following sections, we describe the performance of NIES TM in real global-tracer simulations. The results of model simulations were compared with the data produced by several global tracer-transport model experiments, including the $\mathrm{SF}_{6}$ transport inter-comparison experiment TransCom 2 (Denning et al., 1999) for evaluating largescale/interhemispheric transport, and a comparison with the GLOBALVIEW-CO ${ }_{2}$ dataset (GLOBALVIEW-CO 2,2008 ). We followed specific procedures and specifications established for each test. Table 2 lists the configurations of the NIES TM versions considered in the experiment. The model version with Prather's second-order moments scheme was simulated only with a coarse grid resolution. This model version was not tested with resolutions of $1.25^{\circ}$ and $0.625^{\circ}$ because of high computational costs. The calculations were carried out for 2008 with 4 yr spin-up, because GPV data are a relatively new product that are available only since late 2007.

\subsubsection{Comparison with ${ }^{222} \mathrm{Rn}$ observations}

${ }^{222} \mathrm{Rn}$ is a tracer with a relatively short half-life in the atmosphere of 3.82 days. It has well-known sources and sinks, and has been reasonably well observed around the globe. Hence, the element has been recognized as a useful tracer for evaluating the performance of a transport model over continental and remote oceanic regions. In the WCRP intercomparison experiment (Jacob et al., 1997), short-range transport performance was evaluated using ${ }^{222} \mathrm{Rn}$. We followed the simulation protocol specified in Jacob et al. (1997) and set the surface fluxes of ${ }^{222} \mathrm{Rn}$ to 1 atom $\mathrm{cm}^{-2} \mathrm{~s}^{-1}$ for land between $60^{\circ} \mathrm{S}$ and $60^{\circ} \mathrm{N}$, and to 0.005 atoms cm $\mathrm{cm}^{-2} \mathrm{~s}^{-1}$ for the arctic region between $60^{\circ} \mathrm{N}$ and $70^{\circ} \mathrm{N}$, and for the oceans.

In Fig. 3, summer and winter average concentrations calculated by the NIES TM are compared with observation data reported by Jacob et al. (1997). In a previous investigation (Maksyutov et al., 2008) it was pointed out that the semiLagrangian model version underestimated the ${ }^{222} \mathrm{Rn}$ concentration near the surface and upper levels both in the summer and winter seasons. The flux-form version has significantly improved results for upper and surface layers for the summer season. However, a comparison with results obtained by Zhang et al. (2008) (not shown here) suggests that the concentration at the top of the troposphere is underestimated, as the model does not take into account the cloud penetrative convection that provides tracer transfer up to the tropopause level.

\subsubsection{Comparison with $\mathrm{SF}_{6}$ observations}

In an idealized global transport model field, the atmosphere can be divided into three major regions: the tropics and extratropics in the Northern and Southern Hemispheres (Bowman and Erukhimova, 2004). Particles released in these regions disperse relatively rapidly (several days to several 
Table 2. Configurations of the NIES TMs.

\begin{tabular}{|c|c|c|c|c|}
\hline & \multicolumn{4}{|c|}{ Model } \\
\hline & NIES-08 \SML $\backslash 2.5$ & NIES-08 \VL $\backslash 2.5$ & NIES-08 \VL\0.625 & NIES-08 $\backslash \operatorname{Pr} \backslash 2.5$ \\
\hline \multirow{2}{*}{ Numerical Scheme } & \multirow{2}{*}{ semi-Lagrangian } & \multicolumn{3}{|c|}{ flux-form versions } \\
\hline & & \multicolumn{2}{|c|}{ third-order van Leer } & second-order moments \\
\hline Resolution, deg & 2.5 & 2.5 & 0.625 & 2.5 \\
\hline Number of vertical levels & \multicolumn{4}{|c|}{47} \\
\hline The meteorological dataset & \multicolumn{4}{|c|}{ JMA/GPV dataset } \\
\hline
\end{tabular}
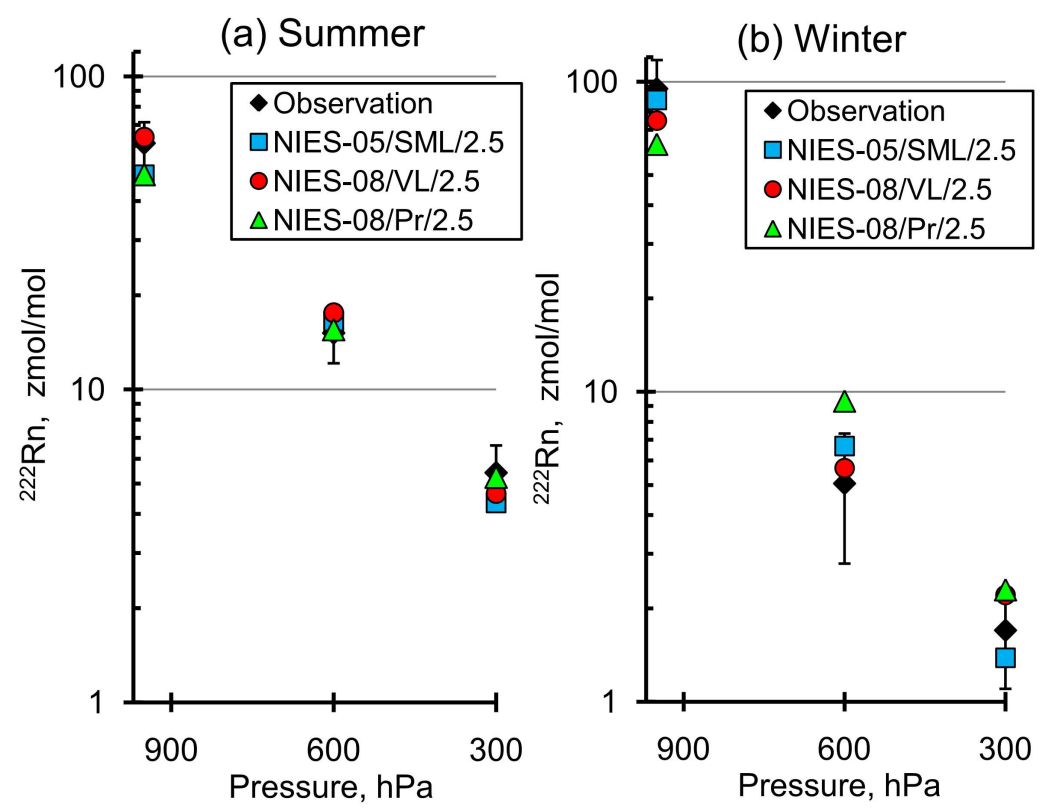

Fig. 3. Comparisons between observations and model simulations of ${ }^{222} \mathrm{Rn}$ averaged concentration over three northern midlatitude continental sites during summer and winter seasons. Results at three vertical levels (mixing layer, $600 \mathrm{hPa}$ and $300 \mathrm{hPa}$ ) are shown. The observation data was obtained by aircraft measurements made at Cincinnati $\left(40^{\circ} \mathrm{N}, 84^{\circ} \mathrm{W}\right)$, Socorro $\left(34^{\circ} \mathrm{N}, 107^{\circ} \mathrm{W}\right)$, and $\mathrm{Kirov}\left(58^{\circ} \mathrm{N}, 49^{\circ} \mathrm{E}\right)$ with the corresponding standard errors.

weeks), while air exchange between the regions proceeds at a slower pace (several weeks to months). Furthermore, the time needed for interhemispheric mixing of the northern and southern extra-tropics is estimated to be nearly 2 years (Geller et al., 1997; Bowman and Erukhimova, 2004). The majority of the sources of anthropogenic pollutants and greenhouse gases are located in the Northern Hemisphere. This distribution of sources, combined with such slow meridional transport, results in a pronounced north-to-south concentration gradient.

$\mathrm{SF}_{6}$, which has a lifetime of over $3000 \mathrm{yr}$, was used as a tracer for validating model transport on an interhemispheric scale. Following the TransCom2 protocol (Denning et al., 1999), we performed a 5-yr simulation with the $\mathrm{SF}_{6}$ emissions taken from the Emission Database for Global Atmospheric Research (EDGAR) (Olivier and Berdowski, 2001).
Figure 4 compares the annual averages of simulated $\mathrm{SF}_{6}$ concentrations, observations from WDCGG (World Data Centre for Greenhouse Gases) (WDCGG, 2008) station listed in Table 3, and data monitored via global atmospheric observations used in the TransCom 2 intercomparison. The TransCom 2 intercomparison used meridional profiles of the simulated and observed 1993 annual mean surface mole fraction of $\mathrm{SF}_{6}$. Observed data include all October/November 1993 Atlantic transect measurements, station locations considered to be within the marine boundary layer, and Izana, which is in the mid-troposphere (Denning et al., 1999). Because tracer patterns correspond to different periods, the annual mean of mixing ratios was normalized to its value at the South Pole. Observation datasets from WDCGG and TransCom2 intercomparison give very different concentrations of $\mathrm{SF}_{6}$ in northern mid-latitudes, because different sets of stations are used. 


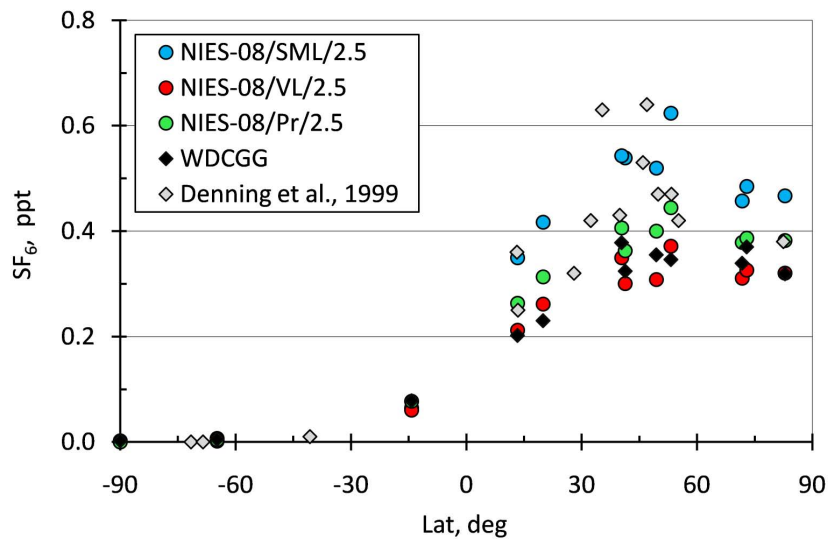

Fig. 4. Interhemispheric gradients of modeled and observed $\mathrm{SF}_{6}$ concentrations. Observations are measurements taken from WDCGG. The annual mean was normalized to its value at the South Pole (SPO) station.

The NIES-08/SML model simulations tend to over-predict the interhemispheric difference indicated by WDCGG observations. Better agreement is found with observations implemented in the TransCom2 intercomparison (Denning et al., 1999). Flux versions of the model show better agreement with up-to-date WDCGG observations that apparently provide a more reasonable interhemispheric gradient.

\subsubsection{Comparison with GLOBALVIEW- $\mathrm{CO}_{2}$}

Evaluation of model performance via $\mathrm{CO}_{2}$ simulations is very complicated because of the high uncertainty in $\mathrm{CO}_{2}$ sources and sinks. However, the TransCom intercomparison studies show the success of such research and provide a useful set of parameters for evaluating both horizontal (interhemispheric) and vertical tracer transport by comparison with established models (Law et al., 1996, 2003, 2008; Denning et al., 1999; Gurney et al., 2003, 2004; Patra et al., 2003a, 2008). In our simulation, we considered up-to-date versions of prescribed $\mathrm{CO}_{2}$ fluxes:

1. emissions due to fossil fuel burning for 2007 with a spatial resolution of $0.5^{\circ} \times 0.5^{\circ}$ (Marland et al., 2007),

2. three-hourly terrestrial biosphere fluxes for 2007 generated from the monthly flux of the CASA ecosystem model (Randerson et al., 1997),

3. sea-air exchange data derived from the climatological mean of $p \mathrm{CO}_{2}$ for 2008 (Takahashi et al., 2009).

The simulation is conducted for 1 yr (2008) from a concentration field at 1 January 2008 prepared using 4-yr spin-up integration with no $\mathrm{CO}_{2}$ in the initial atmosphere. In the spin-up simulation, we used the meteorology for 2008.

Continuous measurements are now conducted at a large number of monitoring stations around the globe, providing
Table 3. List of $\mathrm{SF}_{6}$ measurements sites from WDCGG.

\begin{tabular}{llrr}
\hline Station Name & Code & Latitude, deg & Longitude, deg \\
\hline Alert & ALT & 82.5 & -62.5 \\
Summit & SUM & 72.6 & -38.5 \\
Barrow & BRW & 71.3 & -156.6 \\
Mace Head & MHD & 53.3 & -9.9 \\
Estevan Point & ESP & 49.4 & -126.6 \\
Trinidat Head & THD & 41.1 & -124.2 \\
Niwot Ridge & NWR & 40.0 & -105.5 \\
Mauna Loa & MLO & 19.5 & -155.6 \\
Ragged Point & RPB & 13.2 & -59.4 \\
Tutuila & SMO & -14.2 & -170.6 \\
Palmer Station & PSA & -64.9 & -64.0 \\
South Pole & SPO & -90.0 & -24.8 \\
\hline
\end{tabular}

an opportunity to evaluate and adjust the model. The GlobalView data integration project (GLOBALVIEW- $\mathrm{CO}_{2}, 2008$ ) is a community effort, with the main contribution provided by the Global Monitoring Division (GMD) of the Earth System Research Laboratory of the National Oceanic and Atmospheric Administration (NOAA/ESRL), which conducts sustained observations of the global distribution of atmospheric constituents. GLOBALVIEW data products are designed to enhance the spatial and temporal distribution of atmospheric measurements of $\mathrm{CO}_{2}, \mathrm{CH}_{4}$, and other related atmospheric parameters. These data products are derived from measurements and are specifically intended as tools for use in carboncycle simulation studies. We chose to use data from $35 \mathrm{ma}-$ rine boundary layer sites of GLOBALVIEW-CO2 (2008), which are commonly used in $\mathrm{CO}_{2}$ inversion studies to constrain continental-scale fluxes. The site locations are shown in Fig. 5.

To assess the ability of models to reproduce seasonal variations, we explored the performance of each model in tracking the amplitude and phase of variations. The amplitude of variations is an important factor in terms of model performance, as tested by Patra et al. (2008) for synoptic-scale variations. The normalized standard deviation (NSD) was calculated by dividing the model standard deviation by the observed standard deviation for each station, in order to assess the model's ability to reproduce the amplitude of seasonal variability. The NSD data are shown in Fig. 6. A high degree of consistency between model and measured data is observed in the Antarctic region and in mid- and high-latitude areas of the Northern Hemisphere. The tropical convergence zone is the most challenging region in terms of simulating $\mathrm{CO}_{2}$ variability. Similar results were obtained for the correlation coefficient between modeled and observed data (Fig. 7) used to assess the phase of seasonal variations.

In Antarctica, the seasonal variability has a sleek profile and small amplitude (Fig. 8) because of the lack of significant sources and the dominance of the effect of long-range transport in the balance of the $\mathrm{CO}_{2}$ concentration. The seasonal 


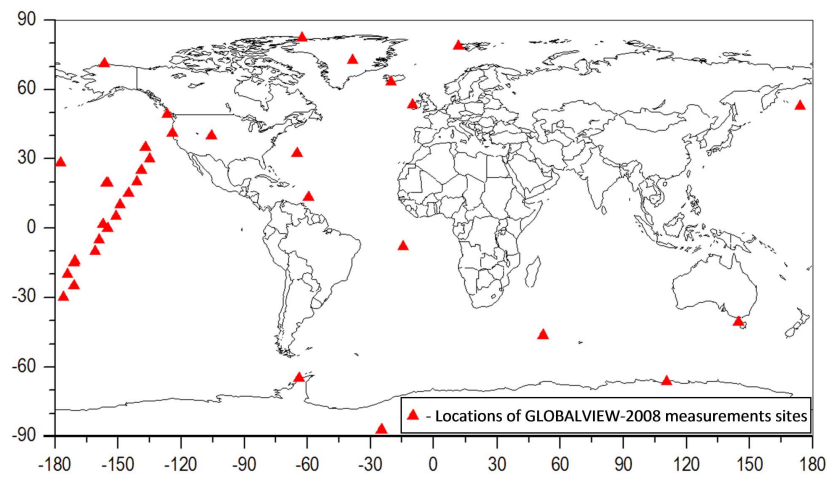

Fig. 5. Locations of GLOBALVIEW-2008 measurement sites. Observed data from those sites were used in comparing with simulated results.

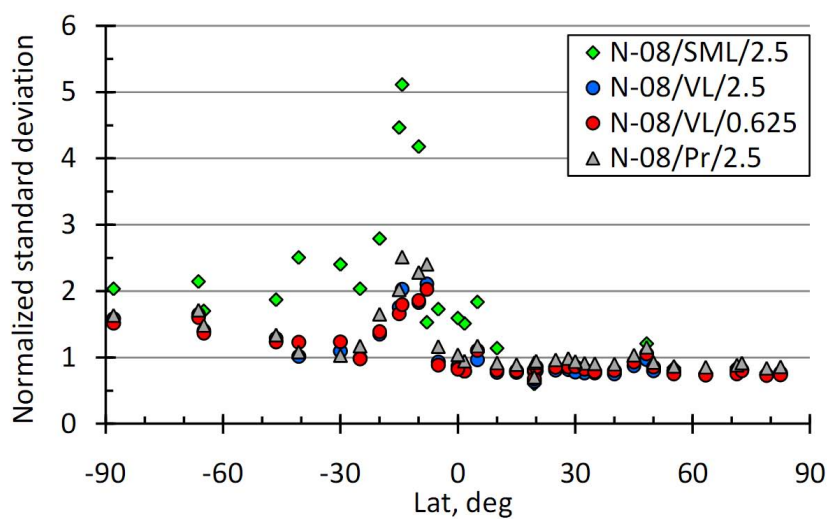

Fig. 6. Normalized standard deviation calculated for the modeled and observed patterns of $\mathrm{CO}_{2}$ for 2008 .

amplitude is defined as the difference between the maximum and the minimum $\mathrm{CO}_{2}$ values in a time series spanning $1 \mathrm{yr}$. The flux versions of the NIES TM are more effective in simulations of long-term transport, because of the mass conservation properties; consequently, in this respect, it has an advantage over the semi-Lagrangian version. However, the actual value of the amplitude of the seasonal cycle is so small that overestimation by NIES-08/SML does not provide a significant contribution to the bias (Figs. 9, 10).

The high density of monitoring stations, homogeneous terrain, and combination of terrestrial biosphere/fossil fuel fluxes in the temperate zone of the Northern Hemisphere result in a high degree of agreement between the model data and observations in this region (Patra et al., 2008). Nevertheless, all the model versions underestimate the concentration in winter (Fig. 9) and overestimate it during summer (Fig. 10).

The challenging regions for simulations are the tropics and mid-latitude areas of the Southern Hemisphere. Stations in these regions are located in marine or coastal areas, meaning that different areas with contrasting $\mathrm{CO}_{2}$ fluxes are located

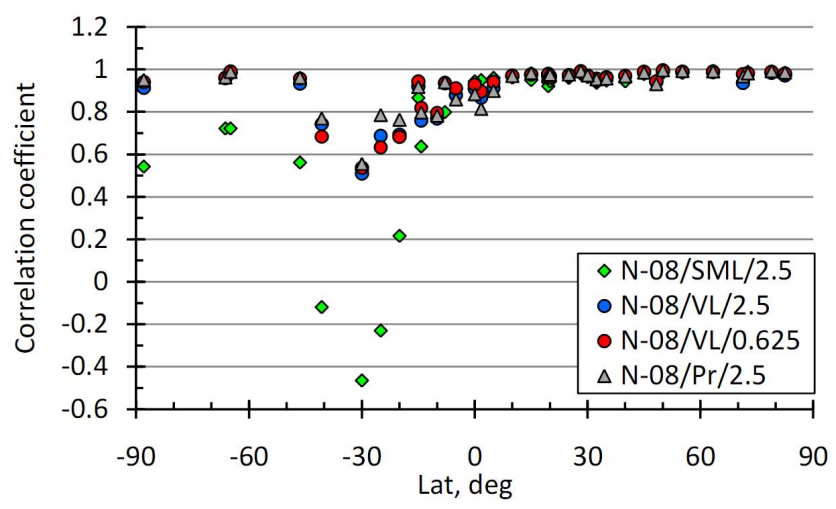

Fig. 7. Correlation coefficients between modeled and observed patterns of $\mathrm{CO}_{2}$ for 2008 .

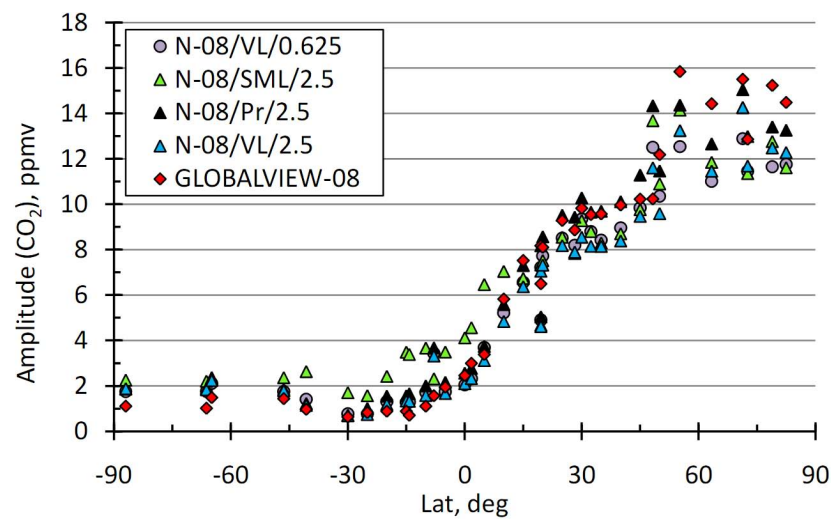

Fig. 8. Amplitude of $\mathrm{CO}_{2}$ seasonal variations for January 2008 (ppmv).

near the stations. Furthermore, the meteorological situation is unstable because of interaction between continental and marine air fluxes. As a result, the degree of agreement between observations and model simulations is dependent on the season. The smaller bias in January compared with July may arise from seasonal changes in meteorology and simplicity in fluxes, as mentioned in Patra et al. (2008).

Application of the flux-form scheme led to a marked improvement in the simulation of seasonal variations in $\mathrm{CO}_{2}$ compared with the semi-Lagrangian approach, especially in Antarctic and tropical regions. Consequently, model bias was reduced and prediction accuracy is close to $4 \mathrm{ppmv}(1 \%)$. A comparison of model versions with resolutions of $0.625^{\circ}$ and $2.5^{\circ}$ showed a slight improvement in the seasonal cycle when using the higher-resolution grid (Fig. 9). Among the other versions, that with a second-order moments scheme performed slightly better than the rest. The results confirm that the second-order moment scheme gives good results using a relatively coarse grid, and that the use of simple numerical schemes (e.g., the three-order van Leer scheme) requires a grid with higher resolution (Bregman et al., 2006). 


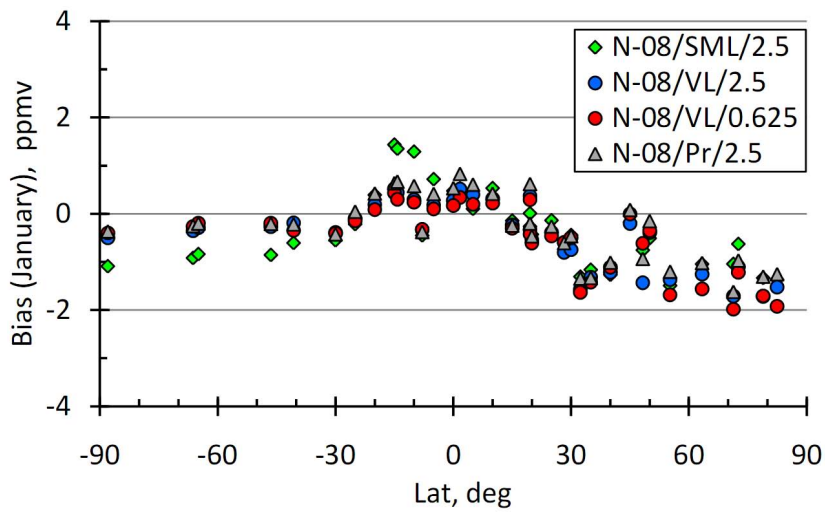

Fig. 9. Monthly averaged $\mathrm{CO}_{2}$ bias (model - observations) for January 2008 (ppmv).

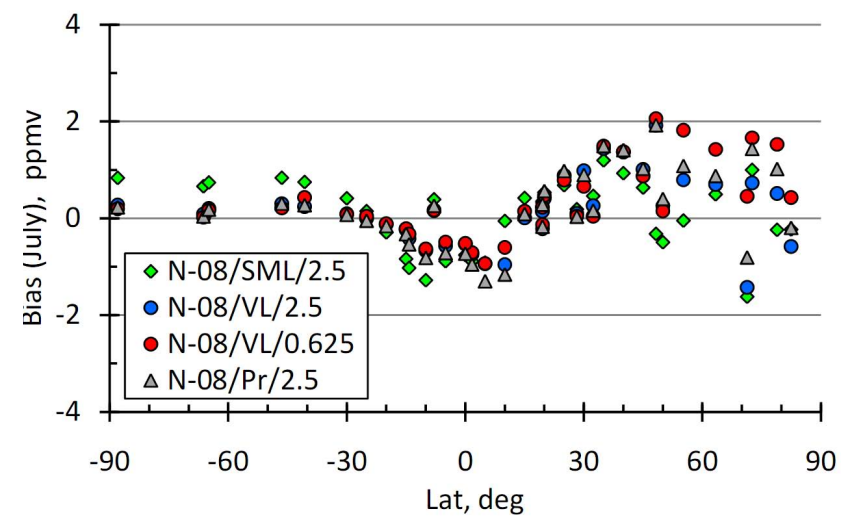

Fig. 10. Monthly averaged $\mathrm{CO}_{2}$ bias (model - observations) for July 2008 (ppmv).

\subsubsection{Comparison of simulations with GFS and GPV data}

We also tested the GPV data in order to identify the influence of meteorological data with a resolution of $0.5^{\circ} \times 0.5^{\circ}$ on the distribution of tracers. A cursory comparison of the GFS and GPV datasets revealed very good agreement in horizontal wind speed, temperature, and pressure, although the height of the planetary boundary layer over oceans and deserts in GFS is approximately 200-500 m higher than that in GPV. Another difference between these data sets is vertical velocity, as stated in Sect. 2.4.

The results of tracer-concentration simulations reveal that the use of GPV data can improve the amplitude of seasonal variations forecasted by the semi-Lagrangian model in the tropics of the Southern Hemisphere (Fig. 11). However, this improvement is accompanied by significant errors, as evident in the correlation coefficients between modeled and observed data for this area (Fig. 12); this result applies not only to the semi-Lagrangian scheme but also to the flux-form scheme. Thus, in the southern tropics, the best results are ob-

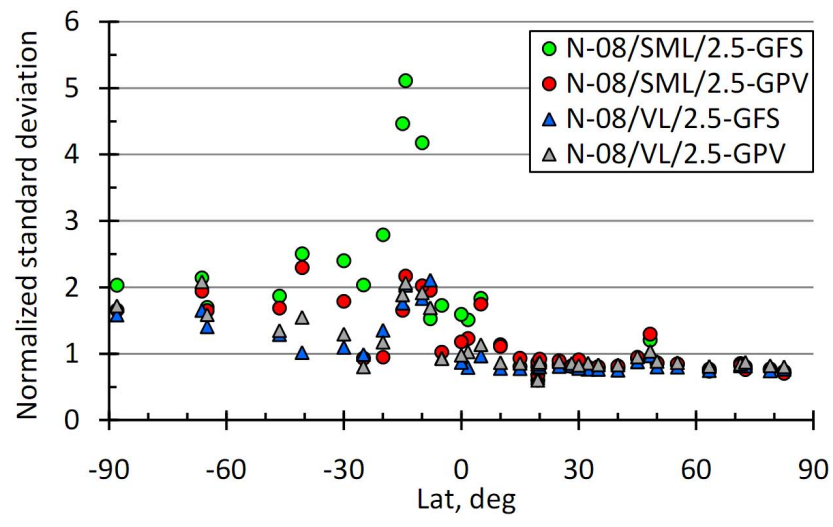

Fig. 11. Normalized standard deviation calculated for the modeled and observed patterns obtained using the GFS and GPV datasets for 2008.

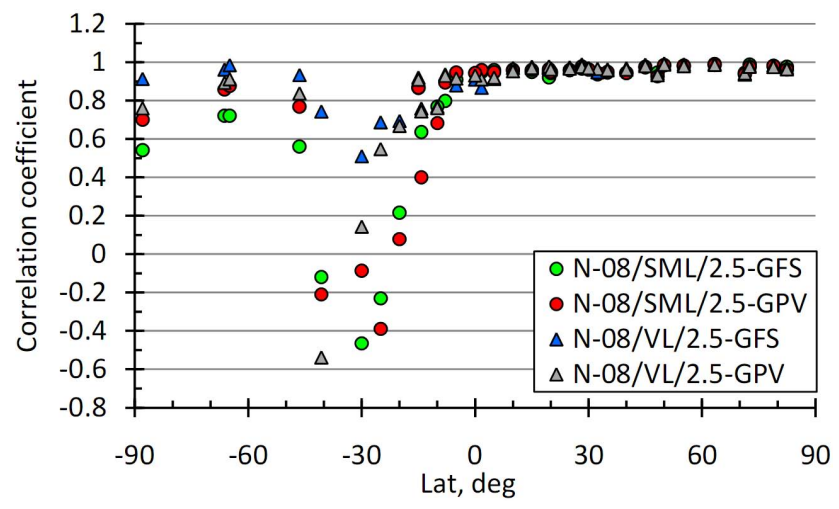

Fig. 12. Correlation coefficient between the modeled and observed patterns obtained using the GFS and GPV datasets for 2008.

tained by a combination of the flux-form scheme with the GFS dataset.

\subsubsection{Simulations with a high-resolution grid}

Using the high-resolution global atmospheric GPV meteorological dataset, with a resolution of $0.5^{\circ} \times 0.5^{\circ}$, it is possible to represent explicitly many smaller-scale phenomena. Figure 13 compares the surface $\mathrm{CO}_{2}$ concentration simulated by NIES-08/VL/0.625 and NIES-08/SML/0.625. Both models appear to be capable of resolving point sources of $\mathrm{CO}_{2}$, such as highly polluted urban areas. The flux-form version tends to merge plumes from multiple sources, as seen in the area of Shanghai (Fig. 13a), because the dispersion associated with time step truncation (CFL criteria) has caused a noticeable distortion in the numerical solution (Ritchie, 1997). Moreover in case of high-resolution simulation, the side effects of the horizontal flux correction method may have a significant importance. The erroneous mass flux corrections may smooth out sharp fluctuations and distort the direction of movement of tracers and as result lead to additional smearing 


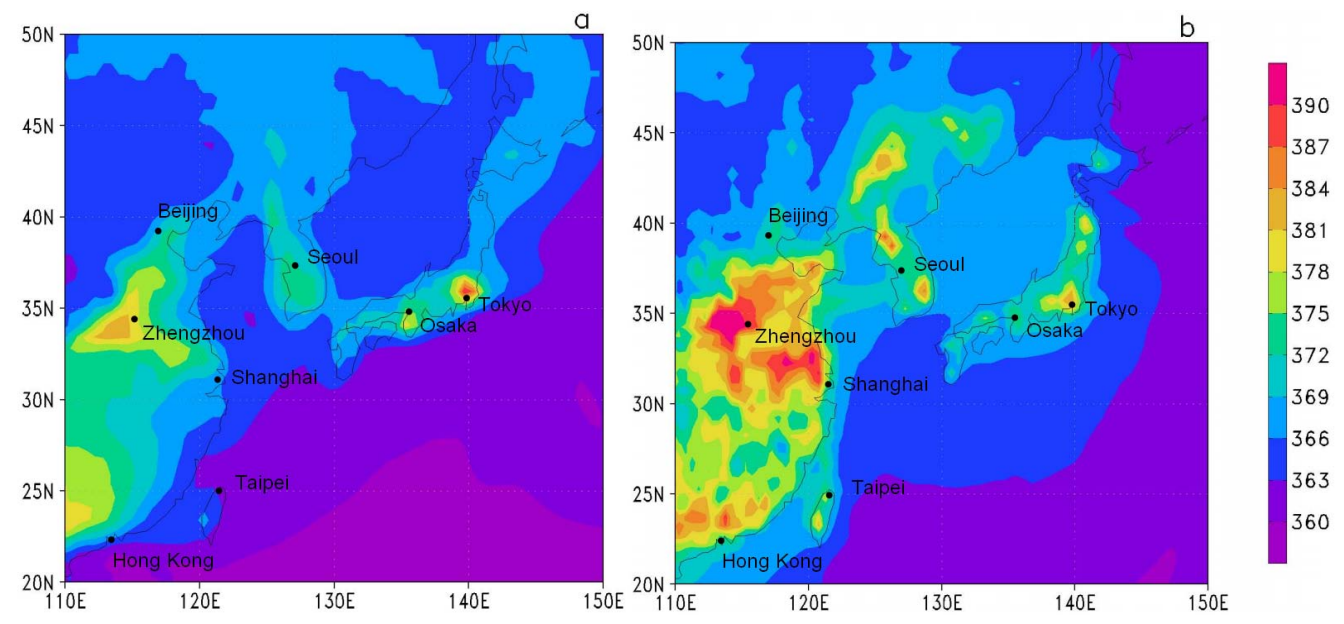

Fig. 13. Simulated surface $\mathrm{CO}_{2}$ concentrations (ppmv) around Japan at 21:00 UTC on 26 March 2008: (a) NIES-05/VL/0.625, (b) NIES05/SLM/0.625.

of the concentration. This effect is similar to action of numerical diffusion. The semi-Lagrangian numerical scheme with less dispersion due to less restricted time step (2-3 time longer than in flux-form version) shows better performance in terms of resolving the sources clearly, as it resolves the plumes from Tokyo, Beijing, Seoul, Shanghai, Hong Kong, Taipei, and other cities (Fig. 13b). For such short-time tracer transport near emission sources, the mass-conservation problem of semi-Lagrangian scheme is less important.

The same conclusions as those above were obtained when considering simulated and observed synoptic variations at Hateruma Island, Japan $\left(24.05^{\circ} \mathrm{N}, 123.81^{\circ} \mathrm{E}\right)$, where continuous measurements have been conducted since October 1993. Hateruma Island is situated in the Pacific Ocean, close to continental Asia, and is influenced by air masses transported from the continent in winter and from the Pacific Ocean in summer (Tohjima et al., 2002). Therefore, the $\mathrm{CO}_{2}$ balance at Hateruma Island is based on local sources (especially from China) and is less sensitive to long-range transport. Our comparison with observed $\mathrm{CO}_{2}$ mixing ratios (Fig. 14) showed that the semi-Lagrangian scheme performs better in reproducing daily variability in concentrations (the correlation coefficient between modeled and observed data is 0.8 ). The advantage of this scheme is the weak dispersion of concentrations found during testing of the numerical schemes. The flux version (NIES-08) is less able to describe sharp fluctuations in concentrations.

\section{Conclusions}

We presented, evaluated, and compared (with a semiLagrangian scheme) the flux-form versions of NIES TM with a third-order van Leer's numerical scheme and second-order moments Prater's numerical scheme on a reduced latitudelongitude grid. The reduced latitude-longitude grid is de-

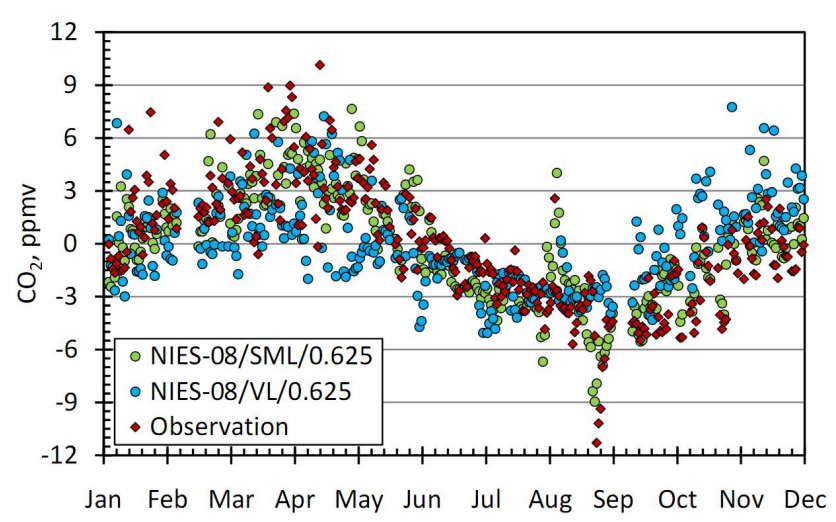

Fig. 14. Daily seasonal cycle of $\mathrm{CO}_{2}$ over Hateruma Island, Japan $\left(24.05^{\circ} \mathrm{N}, 123.81^{\circ} \mathrm{E}\right.$ ) for 2008 (ppmv).

signed to overcome the Courant condition in Polar Regions and to maintain a reasonably large integration time step. Our testing revealed no significant adverse effects associated with implementation of the reduced grid.

An evaluation of the numerical methods, using tests of solid-body rotation on a sphere, showed that van Leer's numerical scheme produces acceptable accuracy, provides mass conservation of the tracers, and yields sufficient performance to conduct long-term simulations with high resolution. To assess the proposed model's ability to forecast tracer concentrations, we performed global transport simulations for ${ }^{222} \mathrm{Rn}, \mathrm{SF}_{6}$, and $\mathrm{CO}_{2}$. With implementation of the flux-form algorithm, improvements were achieved in the simulated interhemispherical gradients of $\mathrm{SF}_{6}$ and $\mathrm{CO}_{2}$. Improvements were also seen in vertical profiles in the upper layers, due to implementation of $\sigma-p$ vertical coordinates. A comparison between simulated seasonal variations in $\mathrm{CO}_{2}$ concentrations and the GLOBALVIEW-CO2 2008 database revealed 
that NIES-08 performs better than its predecessor (NIES TM with a semi-Lagrangian scheme) in reproducing the observed seasonal patterns in the Arctic, Antarctic, and mid-latitude regions.

Nevertheless, this version of the model still does not employ a convective parametrization, which results in insufficient mixing in the free troposphere (Eguchi et al., 2010).

We also tested the $0.5^{\circ}$-resolution GPV dataset prepared by the JMA. In general, the GPV dataset provides a smooth field of vertical wind. Use of the NIES TM with the GPV dataset makes it possible to take into account synoptic-scale effects in the modelling of global transport, and to resolve the point sources of $\mathrm{CO}_{2}$, such as highly polluted urban areas. However, increased horizontal resolution in meteorological models leads to a decrease in the size of the model grid cell and the vertical velocity is resolved horizontally to a greater degree; consequently, the amplitude of vertical velocity increases. Therefore, there are regions with high surface heterogeneity (mountains and coastal regions) where the local vertical velocity is extremely high, slowing the computations of the flux version as a result of limitations in the time step.

Our tests show that the model can be run using a highresolution grid with sufficient perfomance and without loss of precision (e.g., due to numerical diffusion). The accuracy of these calculations will increase with the availability of high-accuracy flux data (e.g., global $1 \times 1 \mathrm{~km}$ fossil fuel $\mathrm{CO}_{2}$ emission inventory; Oda and Maksyutov, 2011) and high-resolution meteorological data (MERRA, Bosilovich et al., 2008). Demand for high-resolution fields of $\mathrm{CO}_{2}$ and other greenhouse gases will also enlarge due to their use as a priori information in retrieval algorithms of observation instruments such as the Atmospheric Infrared Sounder (AIRS) satellite (e.g., Strow and Hannon, 2008) and the Japanese Greenhouse gases Observing SATellite (GOSAT) (e.g., Yokota et al., 2009).

Acknowledgements. The GPV global meteorological analysis data were provided by the Japan Meteorology Agency. For calculations, we used the computational resources of the NIES supercomputer system (NEC SX-8R/128M16). P. K. Patra and Y. Niwa kindly provided the processed surface-flux data. This study was supported by the NIES GOSAT project.

Edited by: P. Jöckel

\section{References}

Baker, D. F., Doney, S. C., and Schimel, D. S.: Variational data assimilation for atmospheric $\mathrm{CO}_{2}$, Tellus, 58B, 359-365, 2006.

Bregman, B., Segers, A., Krol, M., Meijer, E., and van Velthoven, P.: On the use of mass-conserving wind fields in chemistry-transport models, Atmos. Chem. Phys., 3, 447-457, doi:10.5194/acp-3-447-2003, 2003.

Bregman, B., Meijer, E., and Scheele, R.: Key aspects of stratospheric tracer modeling using assimilated winds, Atmos. Chem. Phys., 6, 4529-4543, doi:10.5194/acp-6-4529-2006, 2006.
Bosilovich, M. G., Chen, J., Robertson F. R., and Adler R. F.: Evaluation of global precipitation in reanalyses. J. Appl. Meteor. Climatol., 47, 2279-2299, doi:10.1175/2008JAMC1921.1, 2008.

Bowman, K. P. and Erukhimova, T.: Comparison of global-scale Lagrangian transport properties of the NCEP reanalysis and CCM3, J. Clim., 17, 1135-1146, 2004.

Chipperfield, M. P.: New version of the TOMCAT/SLIMCAT offline chemical transport model: Intercomparison of stratospheric tracer experiments, Q. J. Roy. Meteorol. Soc., 132 (B), 11791203, 2006.

Colella, P. and Woodward, P. R.: The piecewise parabolic method (PPM) for gasdynamical simulations, J. Comput. Phys., 54, 174201, 1984.

Dee, D. P. and Uppala, S.: Variational bias correction of satellite radiance data in the ERA-Interim reanalysis, Q. J. Roy. Meteorol. Soc., 135, 1830-1841, 2009.

Denning, A. S., Holzer, M., Gurney, K. R., Heimann, M., Law, R. M., Rayner, P. J., Fung, I. Y., Fan, S.-M., Taguchi, S., Friedlingstein, P., Balkanski, Y., Taylor, J., Maiss, M., and Levin, I.: Three-dimensional transport and concentration of $\mathrm{SF}_{6}$ : A model intercomparison study (TransCom2), Tellus, 51B, 266297, 1999.

Eguchi, N., Saito, R., Saeki, T., Nakatsuka, Y., Belikov, D., and Maksyutov, S.: A priori covariance estimation for $\mathrm{CO}_{2}$ and $\mathrm{CH}_{4}$ retrievals, J. Geophys. Res., 115, D10215, doi:10.1029/2009JD013269, 2010.

Geller, L. S., Elkins, J. W., Lobert, J. M., Clarke, A. D., Hirst, D. F., Butler, J. H., and Meyers, R. C.: Tropospheric $\mathrm{SF}_{6}$ : Observed latitudinal distribution and trends, derived emissions and interhemispheric exchange time, Geophys. Res. Lett., 24, 675-678, 1997.

GLOBALVIEW-CO ${ }_{2}$, Cooperative Atmospheric Data Integration Project - Carbon Dioxide, CD-ROM, NOAA ESRL, Boulder, Colorado, also available at: ftp.cmdl.noaa.gov, Path: ccg/co2/GLOBALVIEW), 2008.

Gurney, K., Law, R., Scott Denning, A., Rayner, P., Baker, D., Bousquet, P., Bruhwiler, L., Chen, Y.-H., Ciais, P., Fan, S., Fung, I. Y., Gloor, M., Heimann, M., Higuchi, K., John, J., Kowalczyk, E., Maki, T., Maksyutov, S., Peylin, P., Prather, M., Pak, B., Sarmiento, J., Taguchi, S., Takahashi, T., and Yuen, C.-W.: Transcom $3 \mathrm{CO}_{2}$ Inversion Intercomparison: 1. Annual mean control results and sensitivity to transport and prior flux information, Tellus, 55B, 555-579, 2003.

Gurney, K. R., Scott Denning, A., Rayner, P., Pak, B., Baker, D., Bousquet, P., Bruhwiler, L., Chen, Y.-H., Ciais, P., Fung, I. Y., Heimann, M., Higuchi, K., John, J., Maki, T., Maksyutov, S., Peylin, P., Prather, M., and Taguchi, S.: Transcom 3 inversion intercomparison: Model mean results for the estimation of seasonal carbon sources and sinks, Global Biogeochem. Cy., 18, GB1010, doi:10.1029/2003GB002111, 2004.

Hack, J. J., Boville, B. A., Briegleb, B. P., Kiehl, J. T., Rasch, P. J., and Williamson, D. L.: Description of the NCAR community climate model (CCM2), NCAR/TN-382, 108, 1993.

Heimann, M.: The global atmospheric tracer model TM2, Deutsches Klimarechenzentrum (DKRZ), Hamburg, Technical report no. 10, ISSN 0940-9327, 1995.

Heimann, M. and Keeling, C.: A three-dimensional model of atmospheric $\mathrm{CO}_{2}$ transport based on observed winds: 2: Model description and simulated tracer experiments, Geophys. Mon., 55, 
237-275, 1989

Iwamura, K. and Kitagawa, H.: An upgrade of the JMA Operational Global NWP Model, CAS/JSC WGNE Res. Act. in Atmos. and Ocea. Modelling, 38, 6.3-6.4, 2008.

Jacob, D., Prather, M. J., Rasch, P. J., Shea, R.-L., Balkanski, Y. J., Beagley, S. R., Bergmann, D. J., Blackshear, W. T., Brown, M., Chiba, M., Chipperfield, M. P., de Grandpré, J., Dignon, J. E., Feichter, J., Genthon, C., Grose, W. L., Kasibhatla, P. S., Köhler, I., Kritz, M. A., Law, K., Penner, J. E., Ramonet, M., Reeves, C. E., Rotman, D. A., Stockwell, D. Z., Van Velthoven, P. F. J., Verver, G., Wild, O., Yang, H., and Zimmermann, P.: Evaluation and intercomparison of global transport models using ${ }^{222} \mathrm{Rn}$ and other short-lived tracers, J. Geophys. Res., 102(D5), 5953-5970, 1997.

JMA: Outline of the operational numerical weather prediction at the Japan Meteorological Agency. (Appendix to the WMO Technical Progress Report on the Global Data-Processing and Forecasting System and Numerical Weather Prediction). Japan Meteorological Agency, 194, available at: http://www.jma.go.jp/jma/ jma-eng/jma-center/nwp/outline-nwp/index.htm, 2007.

Jöckel, P., von Kuhlmann, R., Lawrence, M. G., Steil, B., Brenninkmeijer, C. A. M., Crutzen, P. J., Rasch, P. J., and Eaton, B.: On a fundamental problem in implementing flux-form advection schemes for tracer transport in 3-dimensional general circulation and chemistry transport models, Q. J. Roy. Meteorpl. Soc., 127, 1035-1052, 2001.

Kalnay, E.: Atmospheric Modeling, Data Assimilation and Predictability, Cambridge University Press, 364, (ISBN-10:0521796296, ISBN-13:978-0521796293), 2002.

Kalnay, E., Kanamitsu, M., and Baker, W. E.: Global numerical weather prediction at the National Meteorological Center, Bull. Am. Meteor. Soc., 71, 1410-1428, 1990.

Kurihara, Y. and Holloway, L.: Numerical integration of a ninelevel global primitive equations model formulated by the box method, Mon. Weather Rev., 95, 509-530, 1967.

Law, R., Rayner, P., Denning, A. S., Erickson, D. Fung, I. Y., Heimann, M., Piper, S. C., Ramonet, M., Taguchi, S., Taylor, J. A., Trudinger, C. M., and Watterson, I. G.: Variations in the modelled atmospheric transport of carbon dioxide and its consequences for $\mathrm{CO}_{2}$ inversions, Global Biogeochem. Cy., 10, $783-$ 796, 1996

Law, R. M., Chen, Y.-H., Gurney, K. R., Baker, D., Bousquet, P., Bruhwiler, L., Chen, Y.-H., Ciais, P., Denning, A. S., Fan, S., Fung, I. Y., Gloor, M., Heimann, M., Higuchi, K., John, J., Maki, T., Maksyutov, S., Peylin, P., Prather, M., Pak, B., Sarmiento, J., Taguchi, S., Takahashi, T., and Yuen, C.-W.: TransCom $3 \mathrm{CO}_{2}$ inversion intercomparison: 2. Sensitivity of annual mean results to data choices, Tellus, 55B, 580-595, 2003.

Law, R. M., Peters, W., Rödenbeck, C., Aulagnier, C., Baker, I., Bergmann, D. J., Bousquet, P., Brandt, J., Bruhwiler, L., Cameron-Smith, P. J., Christensen, J. H., Delage, F., Denning, A. S., Fan, S.-M., Geels, C., Houweling, S., Imasu, R., Karstens, U., Kawa, S. R., Kleist, J., Krol, M., Lin, S.-J., Lokupitiya, R., Maki, T., Maksyutov, S., Niwa, Y., Onishi, R., Parazoo, N., Patra, P. K., Pieterse, G., Rivier, L., Satoh, M., Serrar, S., Taguchi, S., Takigawa, M., Vautard, R., Vermeulen, A. T., and Zhu, Z.: TransCom model simulations of hourly atmospheric $\mathrm{CO}_{2}$ : Experimental overview and diurnal cycle results for 2002, Global Biogeochem. Cy., 22, GB3009, doi:10.1029/2007GB003050, 2008.
Lin, S. J.: A "Vertically Lagrangian" finite-volume dynamical core for global models, Mon. Weather Rev., 132, 2293-2307, 2004.

Lin, S. J. and Rood, R. B.: Multidimensional flux form semiLagrangian transport schemes, Mon. Weather Rev., 124, 20462070, 1996.

Maksyutov, S., Patra, P. K., Onishi, R., Saeki, T., and Nakazawa, T.: NIES/FRCGC global atmospheric tracer transport model: description, validation, and surface sources and sinks inversion, J. Earth Simulator, 9, 3-18, 2008.

Marchand, M., Godin, S., Hauchecorne, A., Lef'evre, F., and Chipperfield, M.: Influence of polar ozone loss on northern midlatitude regions estimated by a high-resolution chemistry transport model during winter 1999/2000, J. Geophys. Res., 108, 8326, doi:10.1029/2001JD000906, 2003.

Marland, G., Boden, T. A., and Andres, R. J.: Global, regional, and national fossil fuel $\mathrm{CO}_{2}$ emissions, Trends: A Compendium of Data on Global Change. Oak Ridge National Laboratory, Information Analysis Center, Oak Ridge, TN, 2007.

Mizuta, R., Oouchi, K., Yoshimura, H., Noda, A., Katayama, K., Yukimoto, S., Hosaka, M., and Kusunoki, S.: 20-km-mesh global climate simulations using JMA-GSM model - Mean climate state, J. Meteor. Soc. Japan, 84(1), 165-185, 2006.

Monge-Sanz, B. M., Chipperfield, M. P., Simmons, A. J., and Uppala, S. M.: Mean age of air and transport in a CTM: Comparison of different ECMWF analyses, Geophys. Res. Lett., 34, L04801, doi:10.1029/2006GL028515, 2007.

Moorthi, R., Sun, H., Xiao, R., Mechoso, C.: Southeast Pacific low-cloud simulation in the NCEP GFS: role of vertical mixing and shallow convection. Office Note 463, National Weather Service, National Centers for Environmental Prediction, 28, available at: http://www.emc.ncep.noaa.gov/officenotes/newernotes/ on463.pdf, 2010.

Nakagawa, M.: Outline of the High Resolution Global Model at the Japan Meteorological Agency. The Technical Review of Typhoon Center of Japan Meteorological Agency, 13, available at: http://www.jma.go.jp/jma/jma-eng/jma-center/ rsmc-hp-pub-eg/techrev/text11-1.pdf, 2009.

Niwa Y.: Numerical study on atmospheric transport and surface source/sink of carbon dioxide, Ph.D. dissertation, The University of Tokyo, 178 pp., 2010

Oda, T. and Maksyutov, S.: A very high-resolution $(1 \mathrm{~km} \times 1 \mathrm{~km})$ global fossil fuel $\mathrm{CO}_{2}$ emission inventory derived using a point source database and satellite observations of nighttime lights, Atmos. Chem. Phys., 11, 543-556, doi:10.5194/acp-11-543-2011, 2011.

Olivier, J. G. J. and Berdowski, J. J. M.: Global emissions sources and sinks, in: The Climate System, edited by: Berdowski, J., Guicherit, R., and Heij, B. J., A. A. Balkema Publishers/Swets \& Zeitlinger Publishers, Lisse, The Netherlands, 33-78, 2001.

Patra, P. K., Baker, D., Bousquet, P., Bruhwiler, L., Chen, Y.-H., Ciais, P., Denning, S. A., Fan, S., Fung, I. Y., Gloor, M., Gurney, K., Heimann, M., Higuchi, K., John, J., Maki, T., Maksyutov, S., Peylin, P., Prather, M., Pak, B., Sarmiento, J., Taguchi, S., Takahashi, T., and Yuen, C.-W.: Sensitivity of optimal extension of observation networks to the model transport, Tellus, 55B, 498511, 2003a.

Patra, P. K., Maksyutov, S., Sasano, Y., Nakajima, H., Inoue, G., and Nakazawa, T.: An evaluation of $\mathrm{CO}_{2}$ observations with Solar Occultation FTS for Inclined-Orbit Satellite sensor for 
surface source inversion, J. Geophys. Res., 108(D24), 4759, doi:10.1029/2003JD003661, 2003b.

Patra, P. K., Peters, W., Rödenbeck, C., Aulagnier, C., Baker, I., Bergmann, D. J., Bousquet, P., Brandt, J., Bruhwiler, L., Cameron-Smith, P. J., Christensen, J. H., Delage, F., Denning, A. S., Fan, S.-M., Geels, C., Houweling, S., Imasu, R., Karstens, U., Kawa, S. R., Kleist, J., Krol, M., Law, R. M., Lin, S.J., Lokupitiya, R., Maki, T., Maksyutov, S., Niwa, Y., Onishi, R., Parazoo, N., Pieterse, G., Rivier, L., Satoh, M., Serrar, S., Taguchi, S., Takigawa, M., Vautard, R., Vermeulen, A. T., and Zhu, Z.: TransCom model simulations of hourly atmospheric $\mathrm{CO}_{2}$ : Analysis of synoptic-scale variations for the period 2002-2003, Global Biogeochem. Cy., 22, GB4013, doi:10.1029/2007GB003081, 2008.

Petersen, A. C., Spee, E. J., van Dop, H., and Hundsdorfer, W.: An evaluation and intercomparison of four new advection schemes for use in global chemistry models, J. Geophys. Res., 103, 19253-19270, 1998.

Prather, M.: Numerical advection by conservation of second-order moments, J. Geophys. Res., 91, 6671-6681, 1986.

Prather, M. J., McElroy, M. B., Wofsy, S. C., Russell, G. L., and Rind, D.: Chemistry of the global troposphere: Fluorocarbons as tracers of air motion, J. Geophys. Res., 92, 6579-6613, 1987.

Prather, M.J., Zhu, X., Strahan, S. E., Steenrod, S. D., and Rodriguez J. M.: Quantifying errors in trace species transport modeling, P. Natl. Acad. Sci., 105(50), 19617-19621, 2008.

Putman, W. M. and Lin S.-J.: Finite-volume transport on various cubed-sphere grids, J. Comput. Phys., 227, 55-78, doi:10.1016/j.jcp.2007.07.022, 2007.

Randerson, J. T., Thompson, M. V., Conway, T. J., Fung, I. Y., and Field, C. B.: The contribution of terrestrial sources and sinks to trends in the seasonal cycle of atmospheric carbon dioxide, Global Biogeochem. Cy., 11, 535-560, 1997.

Rasch, P. J.: Conservative shape-preserving two-dimensional transport on a spherical reduced grid, Mon. Weather Rev., 122, $1337-$ 1350, 1994.

Rasch, P. J., Boville, B. A., and Brasseur, G. P.: A threedimensional general circulation model with coupled chemistry for the middle atmosphere, J. Geophys. Res., 100, 9041-9071, 1995.

Rayner, P. J. and O'Brien, D. M.: The utility of remotely sensed $\mathrm{CO}_{2}$ concentration data in surface inversion, Geophys. Res. Lett., 28, 175-178, 2001.

Ritchie, H.: Application of the Semi-Lagrangian Method to Global Spectral Forecast Models, Numerical Methods in Atmospheric and Oceanic Modelling, NRC Research Press, 445-467, 1997.

Rotman, D. A., Atherton, C. S., Bergmann, D. J., Cameron-Smith, P. J., Chuang, C. C., Connell, P. S., Dignon, J. E., Franz, A., Grant, K. E., Kinnison, D. E., Molenkamp, C. R., Proctor, D. D., and Tannahill, J. R.: IMPACT, the LLNL 3-D global atmospheric chemical transport model for the combined troposphere and stratosphere: Model description and analysis of ozone and other trace gases, J. Geophys. Res., 109, D04303, doi:10.1029/2002JD003155, 2004.

Schoeberl, M. R., Douglass, A. R., Zhu, Z., and Pawson, S.: A comparison of the lower stratospheric age spectra derived from a general circulation model and two data assimilation systems, J. Geophys. Res., 108, 4113, doi:10.1029/2002JD002652, 2003.

Searle, K., Chipperfield, M., Bekkie, S., and Pyle, J.: The impact of spatial averaging on calculated polar ozone loss: 1. Model experiments, J. Geophys. Res., 103, 25397-25408, 1998.

Segers, A., van Velthoven, P., Bregman, B., and Krol, M.: On the computation of mass fluxes for Eulerian transport models from spectral meteorological fields, in: Proceedings of the 2002 International Conference on Computational Science, Amsterdam, The Netherlands, 21-24 April, 766-776, 2002.

Simmons, A., Uppala, S., Dee, D., and Kobayashi, S.: ERAInterim: New ECMWF reanalysis products from 1989 onwards ECMWF, Newsletter No. 110, 25-35, 2006/2007.

Smolarkiewicz, P. K. and Rasch, P. J.: Monotone advection on the sphere: An Eulerian versus semi-Lagrangian approach, J. Atmos. Sci., 48, 793-810, 1991.

Stohl, A., Cooper, O., and James, P.: A cautionary note on the use of meteorological analysis data for quantifying atmospheric mixing, J. Atmos. Sci., 61, 1446-1453, 2004.

Strahan, S. E. and Polansky, B. C.: Meteorological implementation issues in chemistry and transport models, Atmos. Chem. Phys. 6, 2895-2910, doi:10.5194/acp-6-2895-2006, 2006.

Strow, L. L. and Hannon, S. E.: A 4-year zonal climatology of lower tropospheric $\mathrm{CO}_{2}$ derived from ocean-only Atmospheric Infrared Sounder observations, J. Geophys. Res., 113, D18302, doi:10.1029/2007JD009713, 2008.

Takahashi, T., Sutherland, S. C., Wanninkhof, R., Sweeney, C., Feely, R. A., Chipman, D. W., Hales, B., Friederich, G., Chavez, F., Sabine, C., Watson, A., Bakker, D. C. E., Schuster, U., Metzl, N., Yoshikawa-Inoue, H., Ishii, M., Midorikawa, T., Nojiri, Y., Körtzinger, A., Steinhoff, T., Hoppema, M., Olafsson, J., Arnarson, T. S., Tilbrook, B., Johannessen, T., Olsen, A., Bellerby, R., Wong, C. S., Delille, B., Bates, N. R., and de Baar, H. J. W.: Climatological mean and decadal change in surface ocean $\mathrm{pCO}_{2}$, and net sea-air $\mathrm{CO}_{2}$ flux over the global oceans, Deep-Sea Res II, 56(8-10), 554-577, doi:10.1016/j.dsr2.2008.12.009, 2009.

Tohjima, Y., Machida, T., Utiyama, M., Katsumoto, M., Fujinuma, Y., and Maksyutov, S.: Analysis and presentation of in situ atmospheric methane measurements from Cape Ochiishi and Hateruma Island, J. Geophys. Res., 107(D12), 4148, doi:10.1029/2001JD001003, 2002.

van den Broek, M. M. P., van Aalst, M. K., Bregman, A., Krol, M., Lelieveld, J., Toon, G. C., Garcelon, S., Hansford, G. M., Jones, R. L., and Gardiner, T. D.: The impact of model grid zooming on tracer transport in the 1999/2000 Arctic polar vortex, Atmos. Chem. Phys., 3, 1833-1847, doi:10.5194/acp-3-1833-2003, 2003.

van Leer, B.: Towards the ultimate conservative difference scheme. Part IV: A new approach to numerical convection, J. Comput. Phys., 23, 276-299, 1977.

WDCGG: WMO World Data Centre for Greenhouse Gases, Japan Meteorological Agency, Tokyo, available at: http://gaw.kishou. go.jp, 2008.

Williamson, D. L.: Review of numerical approaches for modeling global transport, in: Air Pollution Modeling and its Application IX, NATO Challenges of Modern Society Plenum, 17, edited by: van Dop, H.and Kallos, G., Plenum Press, New York, 377-394, 1992.

Williamson, D. L. and Laprise, R.: Numerical approximations for global atmospheric GCMs, in: Numerical Modeling of Global Atmosphere in the Climate System, edited by: Mote, P. and O'Neil, A., NATO Science Series C 550, Kluwer Academic Pub- 
lishers, 127-220, 2000.

Williamson, D. L. and Rasch, P. J.: Two-dimensional semiLagrangian transport with shape-preserving interpolation, Mon. Weather Rev., 117, 102-129, 1989.

Yang, F., Pan, H.-L., Krueger, S., Moorthi, S., and Lord, S.: Evaluation of the NCEP Global Forecast System at the ARM SGP Site, Mon. Weather Rev., 134, 3668-3690, 2006.

Yokota, T., Yoshida, Y., Eguchi, N., Ota, Y., Tanaka, T., Watanabe, H., and Maksyutov, S.: Global concentrations of $\mathrm{CO}_{2}$ and $\mathrm{CH}_{4}$ retrieved from GOSAT: First preliminary results, SOLA, 5, 160163, doi:10.2151/sola.2009-041, 2009.
Yoshimura, H. and Matsumura, T.: A semi-Lagrangian scheme conservative in the vertical direction, CAS/JSC WGNE Res. Act. in Atmos. and Ocean Modelling, 33, 3.19-3.20, 2003.

Zhang, K., Wan, H., Zhang, M., and Wang, B.: Evaluation of the atmospheric transport in a GCM using radon measurements: sensitivity to cumulus convection parameterization, Atmos. Chem. Phys., 8, 2811-2832, doi:10.5194/acp-8-2811-2008, 2008. 